\title{
O ESPAÇO FORA DO LUGAR: UMA SUPOSTA FILOSOFIA GEOGRÁFICA DO ESPAÇO E DO LUGAR
}

\begin{abstract}
Marquessuel Dantas de Souza ${ }^{1}$
Resumo: O presente texto busca discutir brevemente a ideia de lugar e de espaço no âmbito da Geografia científica, em especial na Geografia Humana. Por sua vez, trás uma contribuição para uma possível filosofia geográfica no que respeita ao discurso sobre ambos os conceitos tão difundidos nos estudos geográficos. Ademais, ressalta-se que a ideia de lugar implica a ideia de sentido espacial. Ao abordar de forma simples o que são espaço e lugar, intenta-se uma reflexão epistemológica, todavia, fazendo valer a geografia humanista ou humanística como o discurso essencial para fundamentar a análise sobre o espaço que envolve o homem como um todo.
\end{abstract}

Palavras-chave: Espaço; Lugar; Filosofia Geográfica; Ontologia.

\section{OUTSIDE SPACE PLACE: AN ALLEGED PHILOSOPHY OF GEOGRAPHIC SPACE AND PLACE}

Abstract: This text seeks to briefly discuss the idea of place and space in scientific Geography, especially in Human Geography. Turn back a contribution to a possible geographical philosophy with regard to the discourse on both concepts so widespread in geographical studies. Moreover, it is noteworthy that the idea of place implies the idea of spatial sense. In addressing simply what are space and place, intends to epistemological reflection, however, enforcing the humanist or humanistic geography as the essential speech to support the analysis of the space surrounding the whole man.

Key words: Space; Place; Geographic Philosophy; Ontology.

\section{INTRODUÇÃO}

Uma filosofia geográfica é uma proposta muita ousada e inovadora. Todavia, podemos dizer o mesmo em relação à ideia de filosofia do espaço e do lugar. - Ambos os termos mencionados - espaço e lugar - são estudados no âmbito da geografia como conceitos fundamentais desta ciência. Com especial atenção na Geografia Humana. Para tanto, poucos são os que realmente discutem os significados epistemológicos e ontológicos dos referidos termos. Esta exposição se propõe como uma espécie de estudo quase metafórica, mítico e transcendental sobre o espaço e o lugar, destarte, invoca uma possível realização psicológica

1. Graduado em Geografia. Faculdade de São Paulo. São Paulo-SP. Estudante do Grupo de Pesquisa Geografia, Literatura e Arte (Geoliterart) da USP (marquessuelgf@gmail.com). 
em se tratando de uma reflexão. Ademais, busca evocar ideias de autores importantes no discurso geográfico no que concerne às noções de espaço e de lugar. Além disso, nos convém situar aqui um detalhe: o espaço fora do lugar, como sugestão, é um título de uma das obras do eminente geógrafo Armando Corrêa da Silva, cuja mesma se configura com um instrumental muito importante sobre o conceito de lugar e, por conseguinte, de espaço. 0 mesmo se pode dizer, evidentemente, de outra obra fundamental do mesmo autor, cujo título De quem é o pedaço? - espaço e cultura. Obra da qual recolhemos muitos ensinamentos epistemológicos. Entre outros trabalhos.

Não obstante, o conceito de lugar e de espaço também é discutido e por uma perspectiva muito singular na geografia de Yi-Fu Tuan. Com efeito, a obra principal no qual estes conceitos são evidenciados filosóficos e psicologicamente intitula-se Espaço e Lugar: a perspectiva da experiência. Obra em que também recolhemos muitos ensinamentos epistemológicos. Portanto, é a partir de uma breve leitura destas três obras em questão, especificamente a de Tuan, que nos propomos dialogar reflexivamente por uma possível filosofia geográfica em torno do que é o espaço e do que é o lugar. - Para o sentido de lugar - logo mais evidenciado -, Lívia de Oliveira nos foi exigida como a autora fundamental. Apesar disso, devemos esclarecer que outros autores também tenham importância, mas aqui quando os citarmos é tão somente como auxiliares ou complementos para o desenvolvimento do tema proposto.

\section{MATERIAIS E MÉTODO}

O texto aqui apresentado se configura como uma breve discussão teórica, quer dizer, ao discorrermos sobre a ideia de espaço e de lugar, evidentemente a mesma envolve reflexão, assim acreditamos, no plano abstrato, isto, com o intuito em atingir uma melhor compreensão dos termos evocados. Assim, além da geografia, a filosofia e a psicologia nos surgem como formas outras de análise do real. Esses campos do saber nos proporcionam um leque amplo de possibilidades para conhecer o mundo.

Grosso modo, a fenomenologia (de Tuan, em especial), nos auxiliará como metodologia. Visto que a ideia de percepção permanece sempre presente. Em outras palavras, a fenomenologia como uma corrente filosófica nos fará assentar a pedra angular que nos 
falta: dialética em relação às noções de espaço e de lugar, significativamente. Decerto, as investigações fenomenológicas de Tuan, especificamente, se manterão como o fundamento de nossa sumária abordagem.

A partir de minuciosa leitura de algumas obras - Armando C. Silva e Tuan, como já apontado

- entendemos engendrar novos olhares sobre o modo de enxergarmos o todo que nos circunda: o mundo. Não obstante, a percepção partindo de nossa sensibilidade como ser existencial nos favorece esse élan entre o mundo-natureza-existencia e nossa realização (ontologia).

Bem entendido, Lugar e Espaço fazem parte de nossa existência, de nossa vida, do nosso ser. Espaço e lugar são extensões do nosso corpo vivo e em movimento recíproco se relacionando com muitos outros corpos-objetos concretos, reais e existenciais.

\section{ESPAÇO E LUGAR: PRELÚDIO FILOSÓFICO}

Dialoguemos sobre a ideia de Lugar "como a primeira qualidade existencial" (OLIVEIRA, 2012, p. 07). Lembrando a ideia de lugar já evocado por Aristóteles. - Como um todo, é neste sentido que partimos para uma breve abordagem em torno do que alguns autores pensaram e pensam sobre o que são lugar e espaço. Sistematicamente sabemos que há trabalhos direcionados para a teoria do espaço, entretanto, Armando Corrêa da Silva nos propõe: "é possível uma teoria do lugar?" (SILVA, 1979, p. XII). Diremos que sim. Mas isto requer muito esforço epistemológico.

De início, consideramos o espaço como o todo, o amplo, o abrangente, o grande e inextenso (relativamente). Acreditamos que o lugar é um ponto fixo 'subjetivamente' no todo, todavia, se constitui como parte inseparável deste todo cósmico. Uma vez que "a parte é espaço do todo, mas perfeitamente localizada" (SILVA, 1986, p. 142). Com efeito, "a Parte é tão complexa quanto o Todo. A Parte é em-si um Todo" (MARTINS, 1996, p. 286). Por vezes, a subjetividade-objetiva permeia ambos os conceitos como possíveis observações creditadas. Diz-se que "o espaço é universal; o lugar é particular" (MARTINS, 2013, supra)*; porquanto, fundando a singularidade espaço-temporal, uma espécie de configuração em que surge consequentemente a ideia de tempo geográfico e espaço histórico. 
Para o geógrafo Yi-Fu Tuan (2013, p. 169) o “lugar é uma pausa no movimento”. A princípio poder-se-ia dizer ser algo sem fundamento, mas em realidade, há uma lógica profunda neste pensamento. Quer dizer, se o lugar é uma estagnação na própria ação, então o espaço é entendido como o próprio movimento: “aberto, livre, amplo, vulnerável provocando medo, ansiedade, desprezo, sendo desprovido de valores e de qualquer ligação afetiva. Já o lugar é fechado, íntimo, humanizado" (SOUZA, 2012, p. 55) ${ }^{3}$. Ou dito de outra forma, "o espaço aberto significa liberdade, promessa de aventura, luz, o domínio público, a beleza formal e imutável, o espaço fechado significa a segurança aconchegante do útero, privacidade, escuridão, vida biológica" (TUAN, 2012, pp. 49-50). De todo modo, "o lugar sendo entendido como território demarcado, personalizado, possuidor de uma aura que atrai ou repele, mas envolve, protege, resguardando as vivências e as experiências de vida, criando ambiências, sendo pausas em movimentos maiores" (SOUZA, 2012, p. 56). Neste sentido, o lugar é o "espaço singular" (SILVA, 1986, p. 99).

Entre o muito amplo e o pouco amplo diremos: "o espaço é mais abstrato do que o lugar" (TUAN, 2013, p. 14), ou melhor, "o espaço é abstrato e o lugar é concreto" (TUAN, 2011, p. 10). Pois "o que começa como espaço indiferenciado transforma-se em lugar à medida que o conhecemos melhor e o dotamos de valor" (TUAN, 2013, p. 14). Ademais, "o lugar é segurança e o espaço é liberdade" (TUAN, 2013, p. 11). - Decerto, "o Espaço é pois o maior lugar possível” (SILVA, 1988, p. 07) "e o Lugar é o menor espaço possível” (SOUZA, 2012, p. 102). Neste contexto, o lugar é mais próximo de nós. Por vezes, "os lugares são centros aos quais atribuímos valor e onde são satisfeitas as necessidades biológicas de comida, água, descanso e procriação" (TUAN, 2013, p. 12), entre outras coisas. Para Gaston Bachelard, "o espaço não é mais que um 'horrível afora-adentro"' (BACHELARD, 1965, p. 275). Ou podemos dizer, de fora para dentro.

Em todo caso, o lugar torna-se realidade a partir de nossa familiaridade com o espaço. Ou seja, "quando o espaço nos é inteiramente familiar, torna-se lugar" (TUAN, 2013, p. 96). Dito

2. Em outros termos: “... se pensamos no espaço como algo que permite movimento, então lugar é pausa; cada pausa no movimento torna possível que localização se transforme em lugar" (TUAN, 2013, p. 14). Portanto, "o lugar é uma pausa no movimento" (TUAN, 2011, p. 15).

3. Uma vez exposto isso, pode-se dizer que "o espaço fechado e humanizado é lugar" (TUAN, 2013, p. 72).

4. "O espaço é o maior lugar possível” (SILVA, 1986, p. 91, grifo do autor). 
por outras palavras; para Tuan "a familiaridade com dada porção do espaço, pela experiência, faz torná-lo lugar" (OLIVEIRA, 2012, p. 11). Com isso, "o espaço transforma-se lugar à medida que adquire definição e significados" (TUAN, 2013, p. 167). Assim, engendra um sentido de lugaridade. Nesta acepção, o lugar "é seguro e familiar" (TUAN, 2014, p. 05), visto possuir um significado. - Com efeito, verifica-se neste momento, que os espaços tais como ruas, parques, praças e etc., a partir do instante que articulam vivências e experiências, ao mesmo tempo em que passam a ser dotados de valores e sentimentos, tornam-se lugares. Para tanto,

O lugar é dado a partir da experiência de cada um, o lugar se apresenta como vivenciado pelos seus habitantes, o lugar, portanto, é constituído a partir da experiência que temos dele. Nesta experiência, está expressa uma relação, sobretudo afetiva, emocional, simbólica e mítica com o lugar (NOGUEIRA, 2001, p. 43).

Diante disso, cada lugar se mostra singular, posto que, em muitas ocasiões se confunde com a paisagem, promovendo um espaço existencial. O lugar é parte essencial de nossa identidade enquanto sujeitos. - "As pessoas carregam os lugares consigo" (NOGUEIRA, citado por SOUZA, 2012, p. 55, grifos nossos). Isto é, em qualquer lugar onde estivermos apresentamos de algum modo, características do lugar onde vivemos. Em virtude deste encadeamento, "cada pessoa está rodeada, carregada por 'camadas' concêntricas de espaço vivido" (BUTTIMER, 1982, p. 178). Cada um tem o seu próprio lugar consigo mesmo. Uma identificação e um pertencimento, por assim dizer, histórico e geográfico único para cada ser (em especial o homem).

Bem entendido, "é na relação intersubjetiva que o lugar vai sendo construído" (NOGUEIRA, 2001, p. 29). Com efeito, "o lugar transcende o ser existencial" (SOUZA, 2012, p. 53). O lugar é revelado por todos nós que o experienciamos através da nossa percepção. De nossa inegável coordenação senso-motora. Percepção esta "tratada como sendo a primeira forma de aquisição do conhecimento sobre o mundo" (NOGUEIRA, 2001, p. 08). Para tanto dir-se-á que "lugar é uma reunião e uma abertura do ser com potencial para a continuidade, mas é constantemente desafiado pelas tecnologias e formas de pensamento que desejam diminuíIo" (RELPH, 2012, p. 31). Entrementes, cada lugar é um pequeno mundo. Neste sentido podemos dizer que "o Lugar é o todo, a síntese entre o universal e o particular" (MARTINS, 1996, p. 304). 
Lugar é um microcosmo. É onde cada um de nós se relaciona com o mundo e onde o mundo se relaciona conosco. O que acontece aqui, neste lugar, é parte de um processo em que o mundo inteiro está de alguma forma implicado, isso é muito existencial e ontológico (RELPH, 2012, p. 31).

A importância do espaço e do lugar é expressiva culturalmente. Sempre houve a preocupação em compreender seus significados. No entanto, faz-se necessário o aprofundamento destes conceitos para melhor entendê-los. Na expressão de Lívia de Oliveira - analisando a importância dos mapas - "não resta dúvida de que o homem, como indivíduo ou como parte de um grupo, basicamente necessita saber onde estão localizadas as coisas e onde ocorrem os acontecimentos na superfície da terra" (OLIVEIRA, 1978, p. 19). Deste modo, necessitam entender os lugares que os rodeiam, numa palavra: precisam compreender o espaço de vivência.

\section{O SENTIDO DE LUGAR}

Como caracterizar o sentido de lugar? O lugar tem um sentido? Qual sentido é esse? Para Tuan, o lugar tem um sentido. Isto é, existe um "sentido de lugar" (TUAN, 2011, p. 09). Todo lugar possui um sentido próprio para habitantes específicos de determinados lugares. $\mathrm{O}$ caráter de um lugar possibilita identificar a imagem de certo lugar (percepção e sentido de localização). Que não deixa de ser, por isso mesmo, um sentido espacial. - Todos os lugares oferecem possibilidades de sentidos diversos (realização: criação, ontologicamente).

O olfato, o paladar, a sensibilidade da pele, a audição, o tato, por exemplo, podem evocar um sentido de lugar radicalmente distinto do da visão. O mesmo pode-se dizer da paisagem sonora de um lugar. Portanto, espaço visual e espaço audível são diferentes. Ademais, "o sentido de lugar implica o sentido de vida e, por sua vez, o sentido de tempo" (OLIVEIRA, 2012, p. 03). Neste contexto a ideia de memória torna-se primordial. Deve-se notar que "lugar e tempo se nos apresentam frequentemente intimamente ligados. Percebemos e sentimos a realidade temporal acoplada ao lugar, ao espacial" (OLIVEIRA, 2012, p. 04). Assim sendo, temos o seguinte: "a concepção atual de lugar é de tempo em espaço; ou seja, lugar é tempo lugarizado, pois entre espaço e tempo se dá o lugar, o movimento, a matéria" (OLIVEIRA, 2012, p. 05, grifo do autor). Além disso, há de ressaltar que "um lugar é algo que se constitui tanto por seu onde como por seu quando" (SARAMAGO, 2012, p. 204, grifo nosso). 
Diante o exposto surge-nos a ideia de mundo vivido, cujo podemos chamá-lo também de espaço vivido. Para tanto, perguntemos: o que é o mundo vivido? Diremos: "o mundo vivido será sempre entendido como lugar vivido, lugar de vida, lugar de existência" (NOGUEIRA, 2001, p. 40). Por conseguinte, “a realidade geográfica é a dos mundos vividos da humanidade" (BESSE, 2014, p. 87). Contudo, o mundo vivido é o lugar onde as coisas acontecem e se relacionam. Em outras palavras, o mundo vivido "é o mundo onde estamos inseridos inegavelmente, por todas as nossas ações como ser existencial" (SOUZA, 2013b, p. 271). Pois ser é existir em algum lugar. "Ser é pertencer. Estar situado. Ter geograficidade" (MARTINS, 1996, p. 305). É estar ciente deste acontecimento. Com efeito, "Ser implica, inescapavelmente, estar em ou pertencer a algum lugar" (SARAMAGO, 2012, p. 204, grifos do autor). Sensivelmente apresentado. Perceptível. Conforme o exposto se diz rigorosamente que "Existir é se correlacionar" (MARTINS, 2013, supra).

Conforme Nogueira, "nos posicionamos pela Geografia ${ }^{5}$ que buscou o lugar não apenas como localização, mas como fenômeno experienciado pelos homens que nele vive" (NOGUEIRA, 2001, p. 19). Para além do comum, “o lugar é experienciado quando há lugar para se mover" (TUAN, 2013, p. 21). Um lugar tem um sentido quando o mesmo é vivenciado por sujeitos que se deslocam no invólucro ou no envoltório locacional, formando uma identidade, uma afetividade com tal lugar. - Migrações pendulares diárias, como se pode observar além das entrelinhas do texto, são exemplos básicos para a compreensão do que está sendo dito.

A experiência expressiva de um lugar se efetiva essencialmente na vivência, na realidade desse lugar. Eis o porquê um lugar ter um sentido, um significado. Um sentido singular para aquele que vivencia um lugar específico. Deveras, para exemplificarmos esta experiência podemos citar, por assim dizer, a seguinte passagem:

Um (a) turista experiência um lugar diferentemente de quem realmente vive ali (um morador local, por exemplo). Diante disso, a discussão sobre "lugar" trás consigo a ideia de identidade, ideia de pertencimento por parte daquele que vive num determinado lugar, e onde o mesmo desenvolve suas

5. Esta Geografia na qual Nogueira se refere é a Geografia com perspectiva fenomenológica, cujos conceitos básicos são Espaço, Lugar e Paisagem. Neste sentido, Edward Relph nos diz que "as bases fenomenológicas da realidade geográfica consistem de três pilares: de espaço, paisagens e lugares, na medida em que são diferentemente experienciados como atributos do mundo-vivido" (RELPH, 1979, p. 18). 
experiências, suas habilidades, suas aptidões para com o real (SOUZA, 2012, p. 53).

Conforme o exposto nota-se que "podemos mudar de lugar, nos desalojarmos, mas ainda é a procura de um lugar" (DARDEL, 2011, p. 41). Por mais que nos distanciemos do nosso lugar de origem ou de vivência, por exemplo, mesmo assim sempre estamos em busca de outro lugar. Neste contexto, coloca-se que o melhor lugar é aquele no qual nós nos sentimos bem. Outrossim, os lugares específicos nos atraem sensivelmente. Deste modo, todo e qualquer lugar infere um sentido singular, já referido. Constituindo espaços identificados. "Espaço e lugar são essencialmente, inseparáveis e permeiam nossas percepções, nossas atitudes e nossos valores de visão de mundo" (OLIVEIRA, 2013, p. 92). Eis, portanto, o sentido espacial de lugar.

\section{O LUGAR E O ESPAÇO: ONTOLOGIA DO SER}

Lugar e espaço são inseparáveis, como referidos anteriormente, assim como espaço e tempo. O espaço e o lugar constitui essencialmente a existência espaço-temporal. - Quando se fala em lugar e espaço, se fala diretamente em tempo. O mesmo acontece quando se diz sobre o tempo, ou seja, promove-se realização no espaço e diretamente em determinado lugar. Contudo, isto se dá preferencialmente nas relações humanas, pois o homem possui intencionalidade intrínseca ao seu ser. Neste sentido, "o espaço é algo que só se coloca em função (da existência) do ser" (MARTINS, 1996, p. 141).

A existência contém o espaço e o lugar e também o tempo. O lugar por ser mais ligado 'materialmente' e 'espiritualmente'-, mais próximo, torna-se o filamento que separa o mundo humano do mundo não humano. Ou melhor, em Geografia o verbo Ser/Estar permanece em constante movimento; a História, por sua vez, invoca memória; embora lembrando que "o tempo especificamente geográfico não é o histórico" (SILVA, 2000, p. 20). Entre um mundo e outro há um elo existencial significativo; de um lado há o mundo humano (homens, humanidade), por outro lado há o mundo natural, a natureza especificamente (elementos existenciais: animais, vegetais, minerais). Ambos embutidos no orgânico e no inorgânico. Assim sendo, o lugar surge transcendentalmente como a essência entre espaço e o tempo; pois não existe coisa não localizada. Uma vez mais, a "unidade homem-mundo" (MOREIRA, 1993, p. 26) dá-se conscientemente num lugar em particular, promovendo assim 
o encantamento relacional do ser-do-homem com a própria natureza ${ }^{6}$. - Todas as coisas estão existencialmente localizadas relacionando-se em determinados lugares, mesmo que sejam apenas mentalmente. Deste modo, "o espaço é o real e o imaginário" (SILVA, 2000, p. 18), ao mesmo tempo. O mesmo pode-se dizer metafisicamente do lugar e do tempo.

Se quisermos fazer alusão a Tuan, o mesmo prioriza o lugar enquanto acesso a intersubjetividade dizendo-nos que "o lugar encarna as experiências e as aspirações das pessoas" (TAUN, citado por NOGUEIRA, 2001, p. 44). Entrementes, "lugar é o mundo vivido" (NOGUEIRA, 2001, p. 44). Deveras, segundo Nogueira, o geógrafo Lowenthal "reconheceu, portanto, o lugar como lugar de vida de cada sujeito" (NOGUEIRA, 2001, p. 45). De todo modo, um lugar apresenta em si características culturais que o diferencia de outros lugares. Pois "o lugar manifesta-se como diferenças e semelhanças, como normalidades e nãonormalidades, como igualdade e desigualdades" (SILVA, 1986, p. 99). Portanto, todo lugar é único.

De acordo com as últimas colocações, considera-se que um lugar é parte essencial de nossa identidade, enquanto sujeitos empíricos. - "Os homens de muitos lugares são reconhecidos pelas características que levam deles através dos componentes culturais: hábito alimentar, linguagem, vestimenta, crenças etc. Assim, o lugar circula, migra..." (NOGUEIRA, 2001, p. 45). Não obstante, "a pessoa se liga ao lugar quando este adquire um significado mais profundo ou mais íntimo" (OLIVEIRA, 2012, p. 12).

Deste modo, o lugar possui significados e valores que não se separam da experiência de quem o habita. Em suma, o lugar é parte essencial de nossa existência. Portanto e, “independente das circunstâncias, cada pessoa é distintamente ela própria” (LOWENTHAL, 1982, p. 134), assim como cada lugar. Em outros termos, cada lugar possui suas características próprias. Por conseguinte, o "lugar é o fenômeno da experiência" (RELPH, 2012, p. 19). Neste sentido diz-se que o "lugar é onde conflui a experiência cotidiana, e também como essa experiência se abre para o mundo" (RELPH, 2012, p. 29). Do mesmo modo podemos dizer que "o lugar é o que reúne e recolhi para si" (SARAMAGO, 2012, p. 223). Segundo esta última passagem, ainda pode-se acrescentar o seguinte comentário: “o

6. Bem entendido, "a territorialidade da natureza é o seu modo de ser geográfico" (MOREIRA, 1993, p. 37). 
lugar é a espacialidade dita mediante a singularidade. O lugar é a territorialidade da contradição entre o universal e o singular. Portanto, o lugar é a dimensão universal do espaço que é posta pela singularidade própria de cada lugar particular" (MARTINS, 1996, p. 304).

Para Nogueira (2001, p. 51) "a relação entre lugar e espaço é construída dialeticamente". A mesma autora salienta que "não queremos aqui pensar o espaço como algo diferente do lugar" (2001, p. 50), assim como conceber "o espaço e o lugar como distintos, sendo aqui novamente enfatizado ser o espaço o desconhecido. À medida que este passa a ser conhecido, dominado, ele se transforma em lugar, lugar vivido" (2001, p. 50). Por conseguinte, "temos interpretado em nossas leituras que espaço e lugar não são coisas distintas, mas também não são sinônimas. Vemos que são categorias que estão sendo utilizadas pela Filosofia, Economia, Geografia, para situar o homem na terra, vinculando-o a ela" (NOGUEIRA, 2001, p. 50), e que essa relação se dá no espaço. Conquanto, "o espaço é existencial [...] e que a existência é espacial" (MERLEAU-PONTY, 2006, p. 394). Muito embora sabendo que,

\begin{abstract}
O espaço nem está no sujeito nem o mundo está no espaço. Ao contrário, o espaço está no mundo à medida que o ser-no-mundo constitutivo da presença já sempre descobriu um espaço. $O$ espaço não se encontra no sujeito nem o sujeito considera o mundo "como se" estivesse num espaço. É o "sujeito", entendido ontologicamente, a presença, que é espacial em sentido originário (HEIDEGGER, 2011, p. 166, grifos do autor).
\end{abstract}

De modo geral, "as ideias de 'espaço' e 'lugar' não podem ser definidas uma sem a outra" (TUAN, 2013, p. 14). Haja vista que "lugar e espaço se imbricam reciprocamente" (SOUZA, 2013a, p. 250). - Ao falarmos de espaço estaremos, por assim dizer, falando de lugar. O mesmo se diz quando falamos de lugar, estaremos evocando explicitamente o espaço (já referido). Para tanto, "refletir sobre o lugar é refletir o seu sentido na geografia" (OLIVEIRA, 2012, p. 15). O mesmo em relação ao espaço e ao tempo: "a Geografia lida com o espaço do tempo presente no espaço" (SILVA, 1986, p. 99). Em síntese, isto quer dizer que "o espaço é tempo do espaço e o tempo é espaço do tempo" (SILVA, 1986, p. 54) ${ }^{7}$. Certamente, "é pelo lugar que nos identificamos, ou nos lembramos, constituindo assim a base de nossa

7. “Expressar o espaço e o tempo em Geografia é realizar a análise dos lugares e das relações” (SILVA, 1986, p. 99). 
experiência no mundo" (MARANDOLA JR., 2012, p. 228). Por meio do lugar conhecemos nosso espaço; através do espaço no qual somos ou estamos habituados, nos conscientizamos sobre o lugar em questão: ideia de pertencimento e de identidade (afinidade explícita com o lugar ou lugares).

“O estudo do lugar é matéria-prima da geografia, porque a consciência do lugar é uma parte imediatamente aparente da realidade [...] O conhecimento do lugar é um simples fato da experiência" (LUKERMANN apud HOLZER, 2012, p. 294). O mesmo pode-se dizer do espaço e da paisagem. Bem como de qualquer outro conceito geográfico. Evidentemente, "a realidade geográfica é, para o homem, então, o lugar onde ele está, os lugares de sua infância, o ambiente que atrai sua presença" (DARDEL, 2011, p. 34). Entrementes, no discurso geográfico que nos cabe neste momento, evocaremos a proposta de Jean-Marc Besse para com a geografia. Para este autor - parafraseando-o - a existência humana é, por assim dizer, naturalizada, geográfica. Besse identifica "A Geografia como Encontro entre a Existência Humana e a Terra" (BESSE, 2014, p. 91, grifos do autor). Uma situação fundante do ser-do-homem e de outros seres existenciais.

Como um todo e explicitamente buscando formular uma suposta filosofia geográfica do espaço e do lugar e, grosso modo, uma possível filosofia da geografia em si, nos convém notar o que se segue notavelmente: "A ciência geográfica é a filosofia da relação entre as partes, pois pensa os Lugares. Ou seja, reflexão do todo" (MARTINS, 1996, p. 308).

\section{RESULTADOS E DISCUSSÃO}

Como resultados expressivos, a discussão como um todo buscou mostrar - de maneira muito simples - o quão o espaço e o lugar nos molda inexoravelmente. Para tanto, requer atenção por parte de seu observador singular: o homem. Com isso, queremos dizer que o ser humano deixa escapar muita coisa em sua volta.

Por conseguinte, por meio da percepção - no sentido amplo - o homem é capaz de alcançar aquilo que tanto deseja: realizar-se. E esta realização dá-se através de sua incessante sede de conhecimento. Ontologicamente o homem transcende o natural quando quer atingir o seu ser. Quase metaforicamente podemos dizer que o homem transcende no espaço e no lugar, assim como no tempo existencial. 
De forma poética diremos que espaço e lugar mantém o homem como o ser-em-si que não cessa de realizar-se. A imaginação, assim como o imaginário faz do homem a imanência ativa de Si. Indubitavelmente toda a discussão resultou numa proposta a ser ampliada (no por vir), uma vez que o estudo - em geral - se manifestou como uma introdução interpretativa em relação aquilo que se pretende mais adiante: desenvolver um estudo mais sistemático sobre o que fora tratado no presente manuscrito.

\section{CONSIDERAÇÕES}

Chegado às palavras finais, diz-se que o estudo sobre o lugar e sobre o espaço é de suma importância para engendrar caminhos outros no que concerne à Geografia, principalmente à Geografia Humana ou Humanista. Como resultado, ao evocar algumas passagens de Armando Corrêa da Silva e de Yi-Fu Tuan, em particular, acreditamos ter dado um passo positivo e bem acentuado em relação ao tema tratado. Consideramos que podemos contribuir, ao menos em parte, para o desenvolvimento filosófico e psicológico do estudo sobre o espaço e o lugar, em Geografia. Nisto, diz-se que se efetuou quase que uma metafísica sobre a ideia de espaço e de lugar.

Acrescentemos ainda que a Geografia Humana - muito em particular - não se preocupando em estudar o espaço como conceito máximo que lhe pertence, torna-se esquizofrênica. Com isto, imaginamos - metaforicamente - uma viagem ulisseia para uma verdadeira filosofia do lugar e do espaço. - Em todo caso, carecemos sistematizar as ideias.

$\mathrm{Na}$ exposição do texto verificou-se como fora possível perceber naturalmente as propostas dialogadas e buscou aplicá-las no cotidiano do mundo. Grosso modo, a Geografia contemporânea necessita sempre colocar em pauta temas como este. Assim, estaremos contribuindo positivamente para uma ontologia do ser-para-a-morte: o homem; no sentido heideggeriano. O ser humano transcende, por exemplo, no espaço e no tempo, no lugar e na paisagem, em suma, na natureza (na existência). Certamente, para essa compreensão o mesmo precisa de ajuda, e o geógrafo é um dos profissionais que pode auxiliá-lo perante sua angústia existencial.

Ao trabalhar com a reflexão filosófica (de cunho fenomenológico, especificamente) o estudante de geografia se depara com muitos questionamentos, é verdade. Bem como se 
depara com uma complexidade de coisas que o deixa confuso. No entanto, devemos lembrar que apenas encarando as coisas com muito compromisso e seriedade é que iremos conquistar uma palavra para o progresso da ciência que estudamos. A Geografia nos faz situar-Ser no mundo. Pensar o espaço e o lugar, bem como pensar outros conceitos geográficos é desenvolver ou fazer avançar a Geografia. Por ora é que compreendemos.

\section{BIBLIOGRAFIA}

BACHELARD, Gaston. La poética del espacio. Primera edición em español. (Traducción de Ernestina de Champourcin). México-Buenos Aires: Fondo de Cultura Económica, 1965. 304p. (Breviarios; 183).

BESSE, Jean-Marc. Ver a Terra: seis ensaios sobre a paisagem e a geografia. $1^{\text {a }}$ reimp. da $1^{\underline{a}}$ ed. (Tradução Vladimir Bartalini) São Paulo: Perspectiva, 2014. 110p. (Coleção Estudos; 230)

BUTTIMER, Anne. Aprendendo o Dinamismo do Mundo Vivido. In: CHRISTOFOLETTI, Antonio (Org.). Perspectivas da Geografia. São Paulo: Difel, 1982. 319p.

DARDEL, Eric. O Homem e a Terra: natureza da realidade geográfica. (Tradução de Werther Holzer) São Paulo: Perspectiva, 2011. 159p. (Estudos; 292)

HEIDEGGER, Martin. Ser e Tempo. 5a edição. (Tradução revisada e apresentação de Márica Sá Cavalcante Schuback; posfácio de Emmanuel Carneiro Leão). Petrópolis: Vozes/Bragança Paulista: Editora Universitária São Francisco, 2011. 598p. (Coleção Pensamento Humano)

HOLZER, Werther. Mundo e Lugar: ensaio de geografia fenomenológica. In: marandol jr. Eduardo; holzer, Werther; oliveira, Lívia de. (Orgs.). Qual o Espaço do Lugar? Geografia, epistemologia, fenomenologia. São Paulo: Perspectiva, 2012. 310p. (Coleção Estudos; 302)

LOWENTHAL, David. Geografia, Experiência e Imaginação: em direção a uma epistemologia geográfica. In: CHRISTOFOLETTI, Antonio (Org.). Perspectivas da Geografia. São Paulo: Difel, 1982. 319p.

MARTINS, Élvio Rodrigues. Anotações de aula. Ontologia e Epistemologia em Geografia. FFLCH/DEGEO-USP, 2013.

Da Geografia à Ciência Geográfica e o Discurso Lógico. Tese de doutorado. Departamento de Geografia, FFLCH - USP. São Paulo, 1996. 319p.

MERLEAU-PONTY, Maurice. Fenomenologia da Percepção. 3a ed. (Trad. Carlos A. R. de Moura) São Paulo: Martins Fontes, 2006. 666p. (Tópicos)

MOREIRA, Ruy. O Círculo e a Espiral: a crise paradigmática do mundo moderno. Rio de Janeiro: Obra aberta, 1993. 142p.

NOGUEIRA, Amélia Regina Batista. Mapa Mental: recurso didático para o estudo do lugar. In: PONTUSCHKA, Nídia Nacib e OLIVEIRA, Ariovaldo Umbelino de (Orgs.). Geografia em Perspectiva. São Paulo: Contexto, 2009. 384p. 
Percepção e Representação Gráfica: A “Geograficidade" nos Mapas Mentais dos Comandantes no Amazonas. Tese de doutorado. Departamento de Geografia da USP. São Paulo, 2001. 181p.

. Mapa Mental: recurso didático no ensino de geografia no 1ำ grau. Dissertação de Mestrado. DEGEO-USP. São Paulo, 1994. 208p.

OLIVEIRA, Lívia de. Sentidos de Lugar e de Topofilia. In: Geograficidade. Niterói, v. 03, no 02, pp. 91-93, inverno, 2013.2 Disponível em: <http://www.uff.br/posarq/geograficidade/revista/index.php/geograficidade/article/view/1 25/pdf>. Acesso em: 22 de janeiro de 2015.

O Sentido de Lugar. In: marandol jr. Eduardo; holzer, Werther; oliveira, Lívia de. (Orgs.). Qual o Espaço do Lugar? Geografia, epistemologia, fenomenologia. São Paulo: Perspectiva, 2012. 310p. (Coleção Estudos; 302)

Estudo Metodológico e Cognitivo do Mapa. Tese de Livre Docência. Universidade de São Paulo. Instituto de Geografia, 1978. 128p.

RELPH, Edward C. Reflexões sobre a Emergência, Aspectos e Essência de Lugar. In: marandol jr. Eduardo; holzer, Werther; oliveira, Lívia de. (Orgs.). Qual o Espaço do Lugar? Geografia, epistemologia, fenomenologia. São Paulo: Perspectiva, 2012. 310p. (Coleção Estudos; 302) abril 1979.

. As Bases Fenomenológicas da Geografia. In: Geografia. Rio Claro, v. 4, no 7, pp. 1-25, SANTOS, Milton. Por uma Geografia Nova: da crítica da geografia a uma geografia crítica. (1a ed. 1978). 6ạ ed. 1a reimpressão. São Paulo: Edusp, 2008. 288p. (Coleção Milton Santos; 2).

SARAMAGO, Lígia. Como Ponta de Lança: o pensamento do lugar em Heidegger. In: marandol jr. Eduardo; holzer, Werther; oliveira, Lívia de. (Orgs.). Qual o Espaço do Lugar? Geografia, epistemologia, fenomenologia. São Paulo: Perspectiva, 2012. 310p. (Coleção Estudos; 302).

SILVA, Armando Corrêa da. A Aparência, o Ser e a Forma (Geografia e Método). In: GEOgraphia, Niterói, v. 02, no 03, pp. 07-25, 2000. Disponível em: $<$ http://www.uff.br/geographia/ojs/index.php/geographia/article/view/27/25>. Acesso em 17 de julho 2011.

. De quem é o pedaço? Espaço e Cultura. São Paulo: Hucitec, 1986.168p. (Coleção Geografia: teoria e realidade).

. O Espaço Fora do Lugar. Segunda edição. São Paulo: Hucitec, 1988. 128p. (Coleção Geografia: teoria e realidade).

Cinco Paralelos e Um Meriadiano: contribuição ao Discurso Geográfico Teórico. (Livre-docência em Geografia). São Paulo: Instituto de Geografia da USP, 1979. 150p.

SOUZA, Marquessuel Dantas de. Geografia e Cultura: o espaço em prosa, mapa literário e imaginação. In: Ra'e Ga, Departamento de Geografia UFPR, Curitiba, v. 28, pp. 242-253, 2013a. Disponível em: <http://ojs.c3sl.ufpr.br/ojs2/index.php/raega/index>. Acesso em 11 de junho 2013.

. Geografia e Fenomenologia: Merleau-Ponty e sua influência na Geografia Humana. In: Caminhos de Geografia. Uberlândia, v. 14, n. 46, pp. 265-272, Jun./2013b. Disponível em: 
<http://www.seer.ufu.br/index.php/caminhosdegeografia/article/view/17889/

$12825>$. Acesso em: 03 de setembro de 2013.

- Geografia e Percepção: uma interpretação introdutória a partir da fenomenologia de Merleau-Ponty. 1a ed. São Paulo: Biblioteca 24 horas, 2012. 134p.

TUAN, Yi-Fu. Espaço e Lugar: a perspectiva da experiência. (Tradução de Lívia de OLIVEIRA) Londrina: Eduel, 2013. 248p.

. Espaço e Lugar, 2013. In: Geograficidade. Niterói, v. 04, no 01, pp. 04-13, verão, 2014. Disponível

em:

<http://www.uff.br/posarq/geograficidade/revista/index.php/geograficidade/article/view/1 57/pdf_1>. Acesso em: 22 de janeiro de 2015.

Topofilia: um estudo da percepção, atitudes e valores do meio ambiente. (Tradução de Lívia de Oliveira) Londrina: Eduel, 2012. 342p.

Espaço, Tempo, Lugar: um arcabouço humanista. In: Geograficidade. Niterói, v. 01, no 01, pp. 08-19, Inverno, 2011. Disponível em: $<$ http://www.uff.br/posarq/geograficidade/revista/index.php/geograficidade/article/view/1 /pdf>. Acesso em: 08 de setembro de 2011.

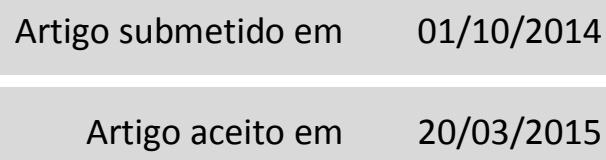

